\title{
Development of Electrochemical Sensor Based on Graphene Oxide Electrode Modified by Silver-Doped ZnO Nanorods for Detection of Carbamate Pesticide in Food
}

\author{
Chunyan Wang ${ }^{1,2, *}$, Qiong Song ${ }^{1,2}$, Xiaoqiu Liu ${ }^{1}$, Xiaowei Zhu ${ }^{1}$ \\ ${ }^{1}$ College of Food Engineering, Jilin Engineering Normal University, Changchun 130052, China \\ ${ }^{2}$ Measurement Biotechnique Research Center, Jilin Engineering Normal University, Changchun, \\ 130052, China. \\ "E-mail: wangchunyan@jlenu.edu.cn
}

doi: $10.20964 / 2020.06 .74$

Received: 6 February 2020 / Accepted: 30 March 2020 / Published: 10 May 2020

\begin{abstract}
A facile approach was used to develop a novel electrochemical sensor based on graphene oxide (GO)/ glassy carbon electrode (GCE) modified by silver ( $\mathrm{Ag}$ )-doped $\mathrm{ZnO}$ nanorods for the determination of carbamate pesticides (CP). The electrochemical deposition technique was used to fabricate the proposed electrode, and scanning electron microscopy and energy dispersive X-ray spectroscopy were carried out to characterize the electrode surface morphology and determine the elements present in the sample, which confirmed the successful formation of Ag-doped $\mathrm{ZnO}$ nanorods. The electrochemical properties were considered by differential pulse voltammetry (DPV) and cyclic voltammetry. Due to the good conductivity and strong catalytic activity of Ag-doped $\mathrm{ZnO}$ nanorods, the developed sensor revealed a limit of detection as low as $0.34 \mathrm{nML}^{-1}$ by DPV, indicating a good stability, acceptable reproducibility and selectivity and great potential in determination of $\mathrm{CP}$ compounds in foodstuffs.
\end{abstract}

Keywords: Graphene oxide electrode; Ag-doped $\mathrm{ZnO}$ nanorods; Differential pulse voltammetry; Carbamate pesticide; Cyclic voltammetry

\section{FULL TEXT}

(C) 2020 The Authors. Published by ESG (www.electrochemsci.org). This article is an open access article distributed under the terms and conditions of the Creative Commons Attribution license (http://creativecommons.org/licenses/by/4.0/). 